\title{
Control in ICT-driven Interaction: Reflections on Symbolic Interactionism
}

\author{
Kofi A Boateng \\ Department of Information Systems and Decision Sciences \\ KNUST School of Business \\ KNUST \\ Kumasi, Ghana
}

\begin{abstract}
Control, for a long time, has been an essential part of organisational sociology. The concept has largely been analysed from different epistemological standpoints. These standpoints are informed by the functional and institutional character of control. Using the postulations of symbolic interactionism as espoused by Herbert Blumer via a qualitative case study, this paper considers the view that fresh insights on control can be derived from the standpoint of ICT-driven interaction in a setting that involves application of mediated technology devices. It is the stance of this paper that people constantly engaged in group activity derive the manner of their behaviour and conduct with both the functional and institutional identity of control that are mutually shaped by sociological and psychological factors. It is therefore important to understand the stream of actions that flow from these imbrications of interactions as they have implications for understanding organisational control from a broader managerial standpoint.
\end{abstract}

\section{Introduction}

The widening use of Information Communication Technologies (ICT) and the techniques of interaction and processing of information have expanded the possibilities of their application in controlling organisational and business processes [1]. As modern organisations continue to dwell heavily on information, innovative methods of control are needed to handle the challenges that characterise the dynamics of information processing. Indeed, control and information are rapidly turning to be allies [1]; hence the ability of individuals to exercise influence in orchestrating behavioural changes may demand an equal measure in information processing and interaction. Subordinates may also have to be in a position to adapt to the conditions of information processing in order to be in a position to ensure the possibility of being controlled in any meaningful sense. This situation necessitates a degree of appreciation of the tenets of symbolic interactionism as espoused by Blumer, because then, meaning is driven by stages of interaction between people [2]. Thus by the understanding of symbolic interactionism the implication of meanings by someone is tied in with their actions in an interpretive process. In this connection symbolic interactionism encourages the view that elucidation is largely driven by the active involvement of a person to choose, analyses, defers, rearranges and changes the meanings against the backdrop of their immediate context in line with the trend of their action. Indeed to Blumer's mind symbolic interactionism underscores the point that interpretation should not be regarded as a mere automatic application of established meanings but a formative process in which meanings are used and revised as instruments for the guidance and formation of action' [2].

These theoretical realities demand juxtaposition with the conditions of ICT-mediated interaction to make sense of different scenarios of control that confront both superiors and subordinates in their everyday situations. Having said this, it is appropriate to bring some insights to bear on the structural foundations of the perspectives of symbolic interactionism consistent with Blumer's original expositions on the concept. These insights are considered significant in an attempt to understand the situational realities of control in mediated technological interaction.

\section{Thematic Constitution of Symbolic Interationism}

Symbolic interactionism views human society as interconnection between human groups or societies, social interaction, objects of which the human is an actor. The central presupposition of this idea is that any evidential system of human society, irrespective of its composition, should account for the fact that human society is premised on the fact that people engage in action. To this end, human behaviour is carried along by both sociological and psychological considerations. The sociological part pins behaviour to such factors as cultural inclinations, norms, sanctions, status symbols, while the psychological aspect involves 
attitudes, motives together with other unseen complexes.

Symbolic interactionism does not merely accept social interaction as given. Rather, social interaction is a process that conditions the conduct of humans instead of being just means or an environment for the demonstration or an outpouring of human conduct. In other words, human interactions consider the actions of one another in a constant stream of actions. This means both personal and group conducts are constituted in, and through an ongoing process. The meaning of objects for people occurs primarily out of the means by which they are defined to them by others with whom they relate.

However, in spite of this reality, the literature on control has been particularly, silent, and largely overlooked the issue of discretion as an integral condition for effective appreciation of control. And this situation is worrying because, then, it restricts our understanding of the concept in the first place. It is important that discretion is given a prominent account in the literature because the very idea of symbolic interaction underscores the power of individuals to make their own decisions in the midst of ongoing interaction process in spite of the presence of sometimes, explicit rules of control that forbid them to take individual decisions without recourse to institutional guidelines or prohibitions.

Secondly, it has the potential to mislead us into thinking that the subordinate is only passive in matters that relate to his/her relationship with their immediate superior. This sense of a lack of active involvement in the mechanics of control has the tendency to make the subordinate conveniently fit what has been observed elsewhere as 'specialists without spirit, sensualities without heart' [3]. This scenario provides the logical frame to suppose that an individual member in the organisation 'cannot squirm out of the apparatus into which he has been harnessed'[4]. However, this is not always the case. It is the stance of this paper that instances exist where the subordinate does not wait to receive specific instructions from a higher authority before they act in the interest of the stated objectives of the organisations in which they find themselves. It is this sense of initiative-taking as an inseparable element of control, at least from the observation of the writer, that has long escaped the attention of researchers and to which this paper seeks to initiate moves as an advocate. For it remains the abiding contention of this paper that fleeting local circumstances, characterised by the dynamics of the moment and many allied considerations can culminate in subordinate gaining superior knowledge and understanding that is entirely alien to the higher authority. Or better still, without the obvious acquiescence of one's immediate superior. And it is this set of conditions that occasions the application of discretion by subordinate in undertaking their legitimate functions. Even though contemporary developments in the use of ICTs have meant the availability of distance-bridging gadgets for the subordinates to keep the centre of authority aware of their particular situation, it has to be borne in mind that still distance has not lost its 'enchantment' and still matters in technology mediated interactions [5].

ICT-driven interaction has gained significant acceptance and momentum as is evidenced in their massive adoption and varied deployment and application in many organisations [6] [7]. Relying on ICTs to mediate interaction between working colleagues in different sections and locations within, and sometimes outside, the layout of an organisation demands an appreciable degree of control and collaboration from the entire organisational machinery. It should be stated ahead of time that control in this work is informed by a "co-ordinating mechanism based on asymmetric relations of power and domination in which conflicting instrumental interests and demands are the overriding contextual considerations" [8]. In other words, the study sees control from laid-down structural guidelines, policies, procedures, rules and set out by the top organisational hierarchy in context-specific situations to achieve stated organisational goals. To this end, control emphasises the unequal balance of power that reinforces the relationship between superiors and subordinates which characterise their day-to-day legitimate organisational rapport.

A key component of technology mediated interaction is the flexibility and the dynamism particularly associated with the many modes of its expression. Part of their flexible nature is demonstrated by their capacity to establish interaction and exchange relations with others not collocated; what can conveniently be described as 'virtual collaboration' [5]. Secondly, these technologies continue to influence, shape and inform the manner in which groups and individuals have come to initiate control strategies to regulate their technology mediated interaction in their everyday working practices.

Indeed, technology mediated interaction can scatter the controlling influence of the top hierarchy that could be instrumental for mutual information exchange, knowledge sharing and work collaboration. The reason for this claim is premised on the presupposition that distance, implied in technology mediated interaction, introduces many challenges such as unfamiliarity of local experience that make direct control of individual and group activities a tricky mission to accomplish [9]. In other words, mediated interaction, in a way, pushes the centre of organisational authority to be more reliant on the members distributed across both defined settings and emerging contexts. Such members have their 
behavioural patterns that are largely unpredictable, and contingent on fleeting circumstances which may not be under direct managerial scrutiny and observation.

\section{Institutional and Functional Identity of Control}

For centuries control has been a central part of organisational sociology and is still considered a fundamental constituent of management theory and organisational studies [10] [11]. This could be due to its significance in the administration of organisations as Filipetti contentiously argues the point that control is the 'most important factor in organisation' [12]. In spite of its widespread application, control is deficient on a common platform of understanding. Consequently, the concept maintains 'scarcely any generally accepted principles and everyone in the field, therefore, works by intuition and folklore' [13]. The contextual malleability of control nonetheless makes it an attractive stream of research since time immemorial in the spheres of philosophy, finance, management and economics literatures [14] [15] [16] [17] [18]. More recently, control has become a fertile ground for research in the field of Information Systems (IS) [19] [20] [21] [22] [23].

Weber saw control as the creation and setting up of structures for monitoring rules by means of a system of hierarchical authority [24]. Thus, Weber's view on control as implying the confinement and the influence of the activities and behaviour of subordinates and the patterns of their interaction in sync with laid-down methodologies unfortunately fails to account for any element of discretion. It is however encouraging to note that subsequent works on control provide detailed analysis of diverse feedback instruments and strategies as part of the entire control picture [17] [25] [26]. It should be noted, though that these researchers while trumpeting the importance of control in the prevention of error inevitably lost sight of the instrumentality of agency in ensuring the effectiveness of control [13] [27].

\subsection{The Control Dilemma}

Organisational scholars have come out with the idea that illustrates the need for a continual process of engagement and negotiation to handle the problems and controversies associated with control [28]. Their concerns happen to reflect the basic tension between strengthening of managerial surveillance of the appropriate work behaviour while concurrently aiming to achieve an appreciable level of voluntary conformity [29]. Hence Rathe clearly declares control as 'one of the thorniest problems of management today' [30].
Nonetheless, one of the key tests in the life of any organisation, and which practically demonstrates the significance of control, is when individuals have, as a matter of necessity, to surrender their wishes and aspirations for the shared interest of the organisation [31]. In order to achieve set targets individuals must be prepared to sacrifice some amount of independence in organisational involvement; and herein lies the fundamental dilemma or the problematic nature of control in organisations.

Control however, acknowledges the logic that individuals and groups by their very nature are often given to evading accepted mode of practice for certain personal desires. Boland observes that control manifests two primary characteristics: one enables while the other restrains [32]. This thought is amplified by Orlikowski with the suggestion that the implantation of control strategies pulls both constraining and enabling strings as a means of dealing with behavioural challenges [19]. To the extent that 'commitment' instead of 'conformity' remains a necessary issue, superiors and managers might be prepared to shift gears and orient towards conditions of 'high trust' as a control strategy [33]. The likely result, Friedman suggests, would be the temperance of autocratic control schemes that may give rise to trust-developing mechanism like improved job discretion [34].

\subsection{Designing Organisational Control}

The administration of control in certain organisations, especially in a sizeable number of software institutions, is designed towards two specific, although contradictory, approaches [20]. The behaviour/outcome control dichotomy constitutes the main structural orientation for inducing organisational configuration, influencing relationships, team performance, effective communication, collaborative undertakings and conflict resolution approaches. Kerr notes that detailed information systems are crystallised and linked up with reward schemes as an attempt to minimise opportunistic tendencies and the pursuit of aims not directly connected with set targets which Snell labels 'myopic behaviour' [35].

The necessity to maintain a working balance between organisational priorities and individual preferences in ICT-driven interaction demonstrates some of the fundamental challenges and tensions in ensuring organisational mediated control. To discuss the administration of control in a working environment with intense reliance on ICTs that support both distributed and local activities calls for consideration of the possible tensions between the exercise of mediated control and the use of discretion.

The difficult situation becomes even more problematic in work characterised by a significant 
degree of uncertainty due to emergent circumstances. An evolving situation has the propensity to give rise to the uncertainty and indeterminacy of administrative objectives at the point of performance. The process therefore demands converting a rule into action, which is an interpretative process of turning abstraction into reality.

Recognising the tension between control and discretion, certain organisational scholars have called for, and observed, a constant negotiation between the centralised authority and the periphery to guarantee that final decision is in tandem with the overall organisation's interests [36]. Coombs and his colleagues specifically suggest reinforcing administrative surveillance techniques while at the same time ensuring uncontrolled acquiescence to minimise the lingering tension between control and the use of discretionary judgments [28]. Indeed, Courpasson is convinced the tension could be conveniently dealt with via his notion of 'soft coercion' [36]. Soft coercion emanates from threats peripheral to actors whose reflexivity is shrouded in their willingness to abide by instructions considered to be the most efficient means of coping with a given situation.

The circumstances of the 'here and now' introduce actors to situations where there are no clear guidelines for taking or favouring a specific course of action. This exemplifies the notion of 'organised complexity' which illustrates the manner work is organised and performed under uncertain, new circumstances that demand pragmatic response because the known, traditional or existing set of imperatives appear inapplicable [37]. Connected with this thought, is the perception that the significant aspect of information necessary for engaging in the most appropriate action could no longer be concentrated within the core of the organisation. Rather, such vital information may emerge and be made use of at the fringes, the place and scene of unfolding events. The unfolding events instigate a constant state of fluidity; thereby orchestrating the organisation's dynamic transformation with a forceful challenge to its traditional understanding. This imagery reflects Mol and Law's metaphoric description of 'fluid spatiality' which adequately captures, and significantly represents, the emergent properties of contemporary organising [38].

\section{Scenes from the Field}

This section of the paper presents a brief account from the field of investigation. The essence is to make it convenient for easy connection be made of the relationship between symbolic interactionism and the repercussions of control against the backdrop of mediated ICT interactions. Adom Foods Services Ltd, hereafter, AFSL, is a medium-sized semi-food processing company situated on the outskirts of a major United Kingdom city. The company prepares semiprocessed foods and sells them to customers found across the various regions of the country. However, bulks of the customers are concentrated within the M25. The M25 is the London Orbital Motorway that stretches to a 117 miles and nearly encircles Greater London.

AFSL customers are predominantly, small-sized restaurant operators. These restaurant operators initiate calls to AFSL's call centre dedicated to processing large volumes of customer orders during a normal working day. During the night shift all such processed orders captured on the database are arranged and packed in large trucks according to a parking arrangement consistent with the proximity of the delivery addresses of the customers. It must be mentioned that when a customer initiates a call to AFSL, the call centre promptly recognises the particular customer as long as the call is made via the customer's landline. Again, this also makes it possible for the customer's order history to be displayed on the screen so that the call centre agent is readily aware of the customer he/she might be dealing with.

Call centre agents are given strict instructions to refrain from processing orders or accounts that are outstanding. Also, the agents are also prohibited from using intemperate language on the phone and therefore are seriously cautioned not to use harsh words even if they receive abusive language from customers. These social etiquettes are crucial for effective customer relationship management techniques. As a means of enforcing these rules of behaviour, the team leaders for different groups of the call centre agents randomly listen in to calls to monitor any potential abuse.

The call centre agents use such technological gadgets as headset, landline, PC and small note pad as part of their daily routine work practices. It is important to stress the point that they apply these tools of technology to communicate with their superiors and colleagues.

\section{Manifest Tensions in Mediated Interactions}

Managing interdependencies through the use of ICTs by sharing and updating the knowledge between the central authority and periphery in a shared sense of situational awareness remain a feasible option. In this situation, the circumstances of the moments suggest the adoption of a different approach that emphasises the importance of constantly negotiating the patterns and processes of work in unpredictable set of circumstances [39]. Therefore discretionary action arises out of the judgement of individuals, contingent on personal conviction which has little to do with past 
experience or predetermined rational rules of logic. It is this contingent aspect of discretion that paints an aspect of control, at least from the standpoint of the controlled, as a process of human reasoning and sense-making, rather than a set of conditions that should be mechanically pursued. Discretion, then, can be argued as being located in the individual which is activated by soul-searching activity and reflection motivated somehow by self-interest, in line with self-referential exercise against the backcloth of Alberts and Hayes idea of 'selfsynchronisation' [40].

Illuminating the concept of selfsynchronisation, Alberts and Hayes make reference to an attempt to increase a subordinate's level of autonomy through his own manoeuvres in anticipating the intentions of his superior should he - the superior - be confronted with a similar circumstance. Though the use of mobile IT can support remote collaboration, the exigencies or the urgency of the situation of distributed employees demand that the use of such distance-bridging devices is temporarily suspended. The temporal suspension of the use of communication devices could hardly be argued to be either planned or accidental. The abandonment therefore prompts a sense of individualisation at the expense of cooperation, and hence a reliance on the self as the basis for undertaking assigned tasks.

A final decision to settle on the self rather than collaboration with the organisation as a starting point for choosing a course of action, according to Simon, is the culminating effect of two opposing factors collectively called stimuli. Each of the factors fights for the psychological attention of the individual in this fashion: 'the stimuli' by which the organisation determines to affect the behaviour of the individual; and the psychological frame of the individual, which establishes his reaction to the stimuli [41]. It is these two-ever opposing stimuli that create the environment for the use of individual discretion. The tensed moment effectively signals the marginalisation of the use of ICT as a coordinating mechanism to create a shared cooperative platform for undertaking corporate mission. This is because the individual comes to depend and trust his own sense of judgement rather than even a remote consideration of the potential benefits of joint assessment prior to performing an assigned task.

This notwithstanding, the use of discretion is not altogether arbitrary; because effective application of discretion is shaped by a certain degree of control just as constructive administration of control is influenced by a considerable dose of discretion. Viewed from this perspective, discretion could be said to carry the weight of the command of the superior, however subtle it may appear to the user, but recognises the volition of the subordinate.
It is fascinating to realise a clear case of the various manifestations of control and the dynamics in which they are administered that the findings from the field study point out. These multifaceted manifestations of control are made possible via psychological conditionalities and effective application and instrumentality of ICT artefacts. The motivations that occasioned these structural control mechanisms are of multivariate sources, indicating the favourable dispositions and the relative strength associated with each. While some of the mechanisms are effective and fruitful in monitoring and securing the required human behaviour, others are found to be inadequate in ensuring compliance to, and demonstration of, recognised behavioural demands expected of both individuals and groups in their various areas of work.

One of the key indicators of control, and the means by which the company seeks to assimilate its staff is to streamline their behaviour through a thorough training programme. The behaviourstreamlining strategy is motivated by standardisation on several fronts: standardisation by work processes, skills and output, all enhanced by division of labour [42]. The training programme is not a one-off event at the resumption of the employee's contractual obligations; in fact, it is the company's core intent to provide ongoing training to all the employees. For, the company is under the impression that with training comes a change in the mental attitude on the part of its staff towards a high sense of allegiance to the cause of its operational undertaking [36]. The motivation for the training, especially, the telesales staff is underpinned by psychological factors that orient and psyche the staff to handle the challenges connected with their job. However the findings from the field readily and amply indicate that there is more to the psychological factors of the training programme. Indeed, findings suggest that results of the training provided in an environment where interaction occurs in an unmediated mode are significantly different from the realities of ICTdriven interaction when the telesales begin their job in real earnest.

A plausible reason that can account for this mismatch could be the mediating and influential role of the technology artefact. The technology artefact is able to provide a platform that allows both parties to communicate what would have been difficult otherwise, had they engaged in armslength, close, face-to-face interaction with each other. The mediating role of the artefact enables anonymity and depersonalisation of the parties involved. The corollary is a probable lack of shared norms of acceptable behaviour, which makes it more likely for the expression of aggressive and unrestrained negative behaviour towards one's interaction partner [43]. A ready example from the 
findings is the abusive language some customers occasionally use when their orders are being taken or their worries and concerns are being addressed on the telephone. The impersonal nature of the mediated communication reveals certain antisocial conducts like verbal resentment, aptly described as 'flaming' [44].

Again the training environment prior to the commencement of one's contractual duties does not mirror the realities of the mediated exchanges that emerge during the call processing periods of actual business operations. The reality of interaction possibilities and the affordances of the mediated ICTs permit the occurrence of certain unanticipated events. For instance, experience of emotional trauma and weeping, premature and sudden termination of telephone calls, swearing and tirades poured on the phone against telesales reps, are indicative of the unpredictable extent to which mediated interaction can degenerate. This means the verbal content alone of the communicated information appears more significant and, arguably, powerful in meaning construction, in the formation of perception and relationship during mediated interaction than the additional visual gestures that collocated interaction usually affords by default [45] [46]. The propinquity of the mediating features of the artefacts provides a psychological nearness that has the potential to generate a bond of affinity between the interaction partners. This could account for the extra-marital relationship that developed between one telesales rep and the wife of one of the company's customers; illustrating the development of interpersonal perceptions facilitated by intense mediated interactions accumulated, presumably over prolonged period.

The communicative flexibility of the ICTs ensures interaction on at least two instances: online and offline which deepen the extent of attraction, interests and commitments of the communicating parties as they negotiate and erect a common communication platform. This resonates with Castells' idea of 'networked individualism' by which technology transforms and varies the organisation and arrangement of social relationships [47]. Long-term relationship (developed as a result of repeated mediated interaction) between two people previously unknown to each other may engender a certain kind of familiarity and relationship. The relationship could become intimate which may mean that those involved negotiate for alternative means of interaction even if it defies prevailing organisational instructions and norms. The exchange of contact numbers between a delivery driver and a customer so that either of them may call to find out when a delivery is due against the expressed prohibition by the company is an abiding example. However, occasionally, the relationship spills over the norms and ethics of business practices and develops into something beyond platonic rapport.

Equally, the request for marriage via the telephone and some of the romantic gestures that sometimes characterise order taking defies and attacks one of the fundamental assumptions of social presence theory. Social presence theory primarily argues that the lesser the number of channels or significatory schemes there are within a given medium, the lesser regard one directs towards their interaction partners [48]. The mediating power of the ICT artefacts in diverse forms of interaction enables and facilitates a high level of social presence, with a relatively high tendency to encourage personal and emotionally charged interaction. This can be accounted for, and exemplified, by the lack of face-to-face nature of ICT interaction. Therefore the generally claimed proposition that computer mediated interaction is lower on social presence as compared to face-toface interaction lends itself to highly contestable arguments. This is because the technology does not prevent emotions and other similar non-verbal cues from being transmitted to the person on the other end of the communication activity.

From the foregoing, technology mediated interaction can achieve the same effect just as faceto-face interaction can if not possibly greater. And messages exchanged via ICTs can influence one's communication partner, possibly, in an equal measure as collocated interaction, an observation radically different from Pena and Hancock who hold that in an online environment '...we cannot use our voice, gestures and gaze to influence others' [49]. It would be safe, then, to argue that essentially, the mediated object grants nearly the same or certain communication effects that make interaction via ICTs appear as though it is face-toface communication.

\subsection{Communication through Control}

A significant number of control strategies that AFSL adopts is mediated through portable and immovable ICTs in the form of mobile telephone, computers, PDAs, laptops, fixed telephones, etc. Essentially, control allows the application of a variety of interaction forms such as email, telephone calls, text messages among others. These strategies are informed by administrative behaviour to the extent that the formulation of various structural procedures to regulate behaviour is geared towards a determined end in a rational format. Thus, the many facets of communication point to administrative rationale for effective control and customer loyalty and retention in their long-term relationship with the company. In the end, AFSL achieves mediated control through different purposeful means of strategic interaction. 


\subsection{Control via Significatory Schemes}

One of the means by which control is manifested is through the specific application of certain significatory schemes for the transmission of standardised, non-negotiable messages or information. Information relayed in this arrangement enables a common interpretative scheme for the intended recipients. A prominent example of this predesigned communication strategy that the study observed is the use of colour code to regulate the order processing activities of telesales reps. Colour in this instance becomes a tool of prohibition; forbidding telesales reps from performing specific duties of selling to a customer whose account is in debt or on hold. A customer's account can be put on-hold if the total amount of ordered items falls below the required daily minimum amount or when an account for which an order has been made has an unfavourable account balance.

For instance the colour 'red' on an account is used to instruct telesales reps not to process any orders associated with such an account as it denotes the indebtedness of the customer to the company. The colour in this sense becomes a tool for imprinting the denotation and reference for adherence to a stated rule. Using a standard colour gives an indication of a standardised message and that a common interpretation frame is applied by the same audience with least regard to the prevailing and emergent nature of the situation. In such a condition, for instance, there is little chance for telesales reps to bring their opinions, beliefs and thoughts to bear on their specific duties even when different situational circumstances present themselves at separate times.

The presence of the significatory scheme(s) therefore limits the extent to which the telesales reps can relate their personal experience on the job to the specific dynamics of its execution. By implication the reference object assumes the status of instrument for the transmission of purposes, plans and meanings [50]. As a result, the symbolic functionality of the reference object (significatory schemes) becomes a symbolic reality of presence [51]. The use of significatory schemes for the expression of authority by means of mediated communication presents certain challenges to people working under administrative authority. It was discovered from the findings, for instance, that when two separate accounts say, A and B are in debt, of about $£ 0.99$ and $£ 100.00$ respectively, processing orders for such accounts would be unsuccessful. For, both accounts are viewed by the same criterion without taking into consideration the significance of the amount involved. The reason stems from the fact that the system has been programmed to flag up and put on hold orders about the situation not the details relating to the particularities of the situation. However the decision to grant and process the order with an almost insignificance magnitude of debt would have to be sanctioned by a reference to, and a permission from, a higher authority.

It should be noted that in spite of his own faculties of reasoning, judgement and initiative, the subordinate is expected to restrain himself from taking such action and depend on the laid down channels of authority to process such orders. The thinking faculties of the subordinate is thus effectively set aside, making him fit Weber's description of 'specialists without spirit and sensualities without heart'[3]. A description that coincides with Simon's reasoning that in such a scenario the subordinate is forced to subject his own judgement and decision making powers in 'abeyance' and makes a detour to official procedures and stated formalities for job performance [41]. Consequently, the degree of specialisation a person has on the job has, if any at all, a very limited impact on the decisions necessary to ensure successful performance as guidelines for carrying out tasks are separated from the contingent decisions that go with it.

The foregoing has a direct implication on trust. When control structures become regimented to the point of being perceived as a symbol of unquestionable trust, placing trust in human judgement is significantly diminished. Indeed human attributes like informed decisions, professional experience and sound judgement are given little room to operate. Trusting the wisdom of systems rather than human expertise seems to pervade and dominate the thinking of not only those promoting the use of such systems but also those applying those systems at the operational level of organisational undertaking.

\section{Conclusions}

The issues in this brief write-up has unquestionably provided a refreshing understanding about the application of ICT in mediated environments that underscores the often taken-for-granted notions about the work that is carried out across time and space in distanciated settings. This text has so far demonstrated using symbolic interactionism as a social lens, we can appreciate the concept of control in ICT-driven interactions from different situational and practical perspectives. While the discussion has unearthed the adoption of portfolio of control mechanisms for ensuring best practice in enterprise-wide activities with regard to the application of both movable and immovable technological devices, it has, at the same time, teased out the many manifestations of interactions, especially, those mediated by ICTs. 
Again, this study has challenged some of the taken for granted assumptions that undergird certain theoretical understandings interaction, such as the social presence theory. Symbolic interaction, for instance has made it altogether clear that interaction is not one massive block of activity waiting to be consummated. Indeed, it is the considered notion of the symbolic interactionism that the use of a certain technology may even be traceable to an unconscious process or inexplicable series and sequences of interactions. It is this very working environment that necessitates and suggests a different control approach for the delivery drivers though, it must be emphasised without any equivocation, the point that the work of these drives is considerably structured. However, a structured work in unpredictable operating conditions changes the picture of control for this group of workers, and therefore demands a different dispensation of control to be effective. The subordinate necessarily has to demonstrate a cooperative behaviour in order for control to be purposefully meaningful. In this wise, the subordinate at the instance of operation is expected to continuously coordinate with the central authority to provide up-to-the minute information on what obtains on the ground. The circumstances of the 'here and now' introduce actors to situations where there are no clear guidelines for taking or favouring a specific course of action. This exemplifies the notion of 'organised complexity' which illustrates the manner work is organised and performed under uncertain, new circumstances that demand pragmatic response because the known, traditional or existing set of imperatives appear inapplicable [37]. Connected with this thought, is the perception that the significant aspect of information necessary for engaging in the most appropriate action could no longer be concentrated within the core of the organisation. Rather, such vital information may emerge and be made use of at the fringes, the place and scene of unfolding events. The unfolding events instigate a constant state of fluidity; thereby orchestrating the organisation's dynamic transformation with a forceful challenge to its traditional understanding. This imagery reflects Mol and Law's metaphoric description of 'fluid spatiality' which adequately captures, and significantly represents, the emergent properties of contemporary organising [38].

Managing interdependencies through the use of ICTs by sharing and updating the knowledge between the central authority and periphery in a shared sense of situational awareness ties in well with the theoretical ideals of symbolic interactionism. The everyday assumption of organisations being perceived in the light of structured routines of collective support for organisational action is fundamentally challenged on this account. What appears to be a fitting description in this particular instance is 'organising' instead of 'organisation' [52]. Organising presents a vivid description which alters the entity formulation of organisations from a static to a process one, emphasising ongoing, recurrent adjustment of work patterns which are "inseparable from the transactional contexts in which they are embedded" [53] [54].

\section{References}

[1] J. R. Beniger, The Control Revolution: Technological and Economic Origins of the Information Society. Cambridge, Massachusetts: Harvard University Press, 1986.

[2] H. Blumer, Symbolic Interactionism: Perspective and Method. Englewood Cliffs, NJ: Prentice-Hall, 1969.

[3] M. Weber, The Protestant Ethic and the Spirit of Capitalism. New York: Scribner's, 1958.

[4] M. Weber, Economy and society: An Outline of Interpretive Sociology. Berkeley, California: University of California Press, 1978.

[5] G. M. Olson and J. S. Olson, "Distance Matters," Human-Computer Interaction, vol. 15, pp. 139-178, 2000.

[6] G. Morgan, Images of Organisation Thousand Oaks, California: Sage Publications, 1997.

[7] J. Pfeffer, In Managing with Power: Politics and influence in organisations. Boston, Massachusetts: Harvard Business School Press, 1992.

[8] M. I. Reed, "Organization, Trust and Control: A Realist Analysis," Organization Studies, vol. 22, pp. 201228, 2001.

[9] M. O'Leary, W. Orlikowski, and J. Yates, "Distributed Work over the Centuries: Trust and Control in the Hudson's Bay Company, 1670-1826," in Distributed Work, P. J. Hinds and S. Kiesler, Eds. Cambridge, Massachusetts: The MIT Press, 2002, pp. $27-$ 54.

[10] R. Simons, Levers of Control: How managers use innovative control systems to drive strategic renewal. Boston, Massachusetts: Harvard Business School Press, 1995.

[11] J. Yates, Control through Communication: The Rise of System in American Management. Baltimore, Maryland: The Johns Hopkins University Press, 1989.

[12] G. Filipetti, Industrial Management in Transition. Homewood, ILL: Irwin, 1946.

[13] R. N. Anthony, Planning and Control Systems: A Framework for Analysis. Boston, Massachusetts: Harvard University Press, 1965. 
[14] G. Hofstede, "The Poverty of Management Control Philosophy," The Academy of Management Review, vol. 3, pp. 450-461, 1978.

[15] R. G. Hunt and I. S. Rubin, "Approaches to Managerial Control in Interpenetrating Systems: The Case of Government-Industry Relations," The Academy of management Journal, vol. 16, pp. 296-311, 1973.

[16] P. N. Khandwalla, "Effect of Competition on the Structure of Top Management Control," The Academy of Management Journal vol. 16, pp. 285-295, 1973.

[17] K. M. Eisenhardt, "Control: Organizational and Economic Approaches," Management Science, vol. 31, pp. 134-149, 1985.

[18] R. E. Hoskisson and T. A. Turk, "Corporate Restructuring: Governance and Control Limits of the Internal Capital Market," The Academy of Management Review, vol. 15, pp. 459-477, 1990.

[19] W. J. Orlikowski, "Integrated information environment or matrix of control? The contradictory implications of information technology," Accounting, Management and Information Technology, vol. 1, pp. 942, 1991.

[20] S. R. Nidumolu and M. R. Subramani, "The Matrix of Control: Combining Process and Structure Approaches to Managing Software Development," Journal of Management Information Systems, vol. 20, pp. 159-196, 2003

[21] L. J. Kirsch, "Developing Common Systems Globally: The Dynamics of Control," Information Systems Research, vol. 15, pp. 374-395, 2004.

[22] L. Graham, "Manual Workers: Conflicts and Control," in The Oxford Handbook of Work and Organization, S. Ackroyd, R. Batt, P. Thompson, and P. S. Tolbert, Eds. Oxford: Oxford University Press, 2005, pp. 339-355.

[23] G. Wiredu and C. Sorensen, "The Dynamics of Control and Mobile Computing in Distributed Activities," European Journal of Information Systems, vol. 15, pp. 307-319, 2006.

[24] M. Weber, The Theory of Social and Economic Organization. Glencoe, IL: The Free Press, 1974.

[25] W. G. Ouchi and M. A. Maguire, "Organizational Control: Two Functions," Administrative Science Quarterly, vol. 20, pp. 559-569, 1975.

[26] W. G. Ouchi, "The Relationship Between Organizational Structure and Organizational Control," Administrative Science Quarterly, vol. 22, pp. 95-113, 1977.

[27] K. M. Eisenhardt, "Making Fast Strategic Decisions in High-Velocity Environments," Academy of Management Journal, vol. 32, pp. 543-576, 1989.

[28] R. Coombs, D. Knights, and H. C. Willmott, "Culture, Control and Competition: Towards a
Conceptual Framework for the Study of Information Technology in Organizations," Organization Studies, vol. 13, pp. 51-72, 1992.

[29] R. Crompton, "Deskilling of Clerical Work." Oxford: University of Oxford, 1978.

[30] A. W. Rathe, "Management Controls in Business," in Management Control Systems, D. G. Malcolm and A. J. Rowe, Eds. New York: Wiley, 1960.

[31] C. Barnard, The Functions of the Executive. Cambridge, Massachusetts: Harvard University Press, 1956.

[32] J. R. Boland, "Control causality and information systems requirements," Accounting, Organizations and Society, vol. 4, pp. 259-272, 1979.

[33] A. Fox, Beyond contract: work, power and trust relations. London: Faber and Faber, 1974.

[34] A. Freidman, "The means of management control: a critical note on Storey," Sociology, vol. 21, pp. 287-294, 1987.

[35] J. L. Kerr, "Diversification strategies and managerial rewards: An empirical study," Academy of Management Journal, vol. 28, pp. 155-179, 1985.

[36] D. Courpasson, "Managerial Strategies of Domination. Power in Soft Bureaucracies," Organization Studies, vol. 21, pp. 141-161, 2000

[37] W. Weaver, "Science and Complexity," American Scientist, vol. 36, pp. 536 - 544, 1948.

[38] A. Mol and J. Law, "Regions, Networks and Fluids: Anaemia and Social Topology," Social Studies of Science, vol. 24, pp. 641 - 671, 1994

[39] K. E. Weick, Sensemaking in organizations. Thousand Oaks, CA: Sage, 1995.

[40] D. S. Alberts and R. E. Hayes, Power to the Edge: Command and Control in the Information Age. Washington, DC: CCRP Publication Series, 2003.

[41] H. Simon, Administrative Behavior: A Study of Decision-making Processes in Administrative Organizations, Fourth edition ed. New York: The Free Press, 1997.

[42] H. Mintzberg, Structure in Fives: Designing Effective Organizations. Englewood Cliffs, New Jersey: Prentice-Hall, 1983.

[43] L. Sproull and S. Kiesler, Connections: new ways of working in the networked organization. Cambridge, Mass: MIT Press, 1991.

[44] J. Siegel, V. Dubrovsky, S. Kiesler, and T. W. McGuire, "Group processes in computer-mediated communication," Organizational Behavior and Human Decision Processes, vol. 37, pp. 157 - 187, 1986. 
[45] J. T. Hancock and P. J. Dunham, "Language use in computer-mediated communication: The role of coordination devices," Discourse Processes, vol. 31, pp. 91-110, 2001.

[46] J. B. Walther, "Interpersonal Effects in ComputerMediated Interaction: A Relational Perspective," Communication Research, vol. 19, pp. 52-90, 1992.

[47] M. Castells, The Internet Galaxy: Reflections on the Internet, Business, and Society. Oxford: Oxford University Press, 2001.

[48] J. B. Walther and J. K. Burgoon, "Relational communication in computer-mediated interaction," Human Communication Research, vol. 19, pp. 50-88, 1992.

[49] J. F. Pena and J. T. Hancock, "Relational Control in Computer-Mediated Groups: An Interactional Approach to Dominance Perceptions in Distributed and Collocated Groups," in International Communication Association. Dresden International Congress Centre, Dresden, Germany: allacademic, 2008.

[50] G. C. Bowker and S. L. Star, Sorting things out: Classification and its consequences. Cambridge, MA: MIT Press, 1999.

[51] A. Borgmann, Holding On to Reality: The Nature of Information at the Turn of the Millennium. Chicago: The University of Chicago Press, 1999.

[52] R. W. Scott, "Reflections on a Half-Century of Organizational Sociology," Annual Review of Sociology, vol. 30, pp. 1 - 212004.

[53] K. E. Weick, The Social Psychology of Organizing. Reading, MA: Addison-Wesley, 1979.

[54] M. Emirbayer, "Manifesto for a relational sociology," American Journal of Sociology, vol. 103, pp. 281 - 317, 1997. 